\title{
Ultrastructual Characteristics of an Established Hepatocyte Cell Line with Typical Epithelial Morphology
}

\author{
Yasuhiko Tsunematsu, Masanori Iwadare*, Wakako Endo* and Kiyoaki \\ Kamijo* \\ Department of Applied Biological Science, Faculty of Science and Technology, \\ Science University of Tokyo, Noda 278, and *Department of Tissue Culture \\ and Virology, Juntendo University School of Medicine, Tokyo 113, Japan
}

\begin{abstract}
An epithelial cell line (RLC1005) derived from normal fetal rat liver has been established. The cells are polygons and show intimate cell to cell adhesion. Electron microscopy showed that they are similar to hepatocytes, because of the presence of glycogen granules and of smooth surface ER, and the presence of intercellular structures similar to the bile canaliculi found in situ.
\end{abstract}

Mammalian livers have been utilized widely to test the toxicity of a variety of drugs, because detoxication is a liver-specific function. However, lack of controlled experimental conditions in vivo has restricted our understanding of the processes involved. In vitro cell culture systems, therefore, might be useful for analizing the mechanism of drug actions. A number of successful cultures of liver cells, which retain part of the differentiative traits of livers, recently have been done $(4,6)$. We have focused our attention on establishing liver cell lines in vitro that retain specific characteristics of liver functions in situ. We here describe the morphology and ultrastructural characteristics of an epithelial cell line derived from fetal livers.

Liver cells were dissociated from 15-day-old fetuses of Wistar rats (5), then $10^{5}$ cells were inoculated into a $60 \mathrm{~mm}$ Falcon petri dish containing Ham's F12 medium (NISSUI) supplemented with four-fold concetrations of amino acids and $10 \%$ fetal bovine serum (Flow Laboratories). Cultures were maintained at $37^{\circ} \mathrm{C}$ in a humidified atmosphere of $5 \% \mathrm{CO}_{2}$ and $95 \%$ air. For the continuous subcultures, confluent cultures were trypinized and seeded at a density of $2 \times 10^{5}$ cells every 10-14 days. For electron microscopy, cultures were fixed with $1.5 \%$ glutaraldehyde and $1.0 \% \mathrm{OsO}_{4}$

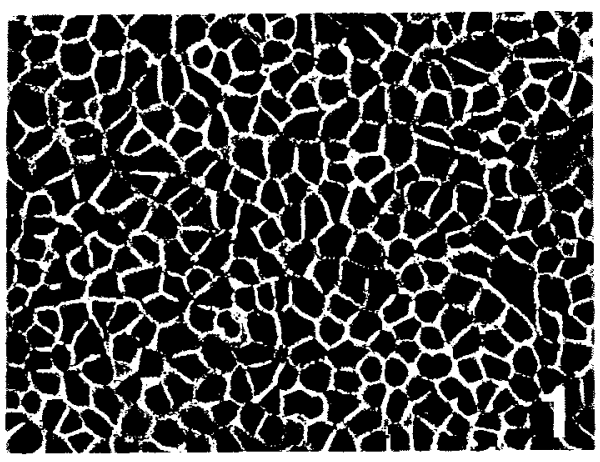

Fig. 1. Fetal liver cells seen after 350 days of culture. $\times 250$ 

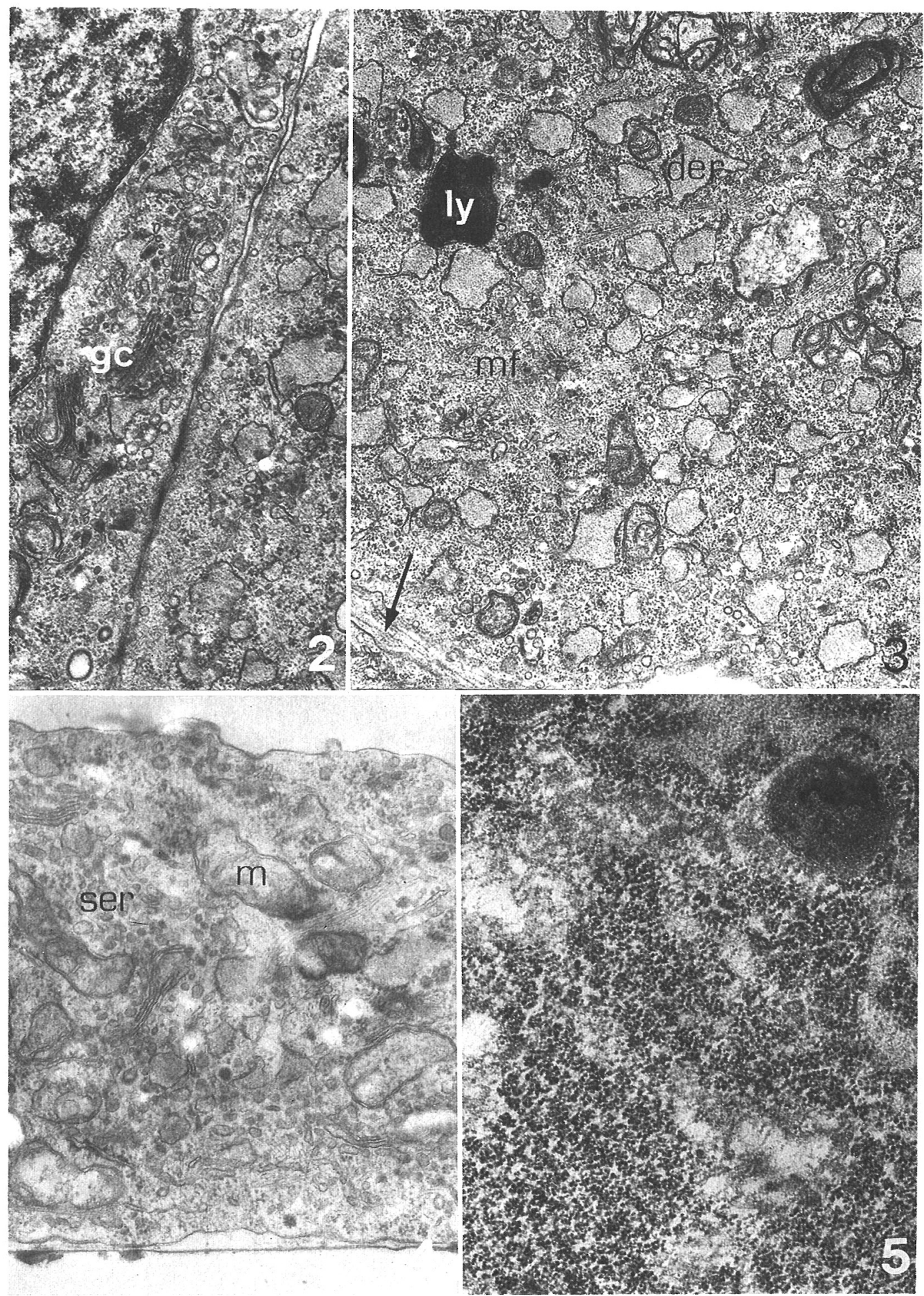


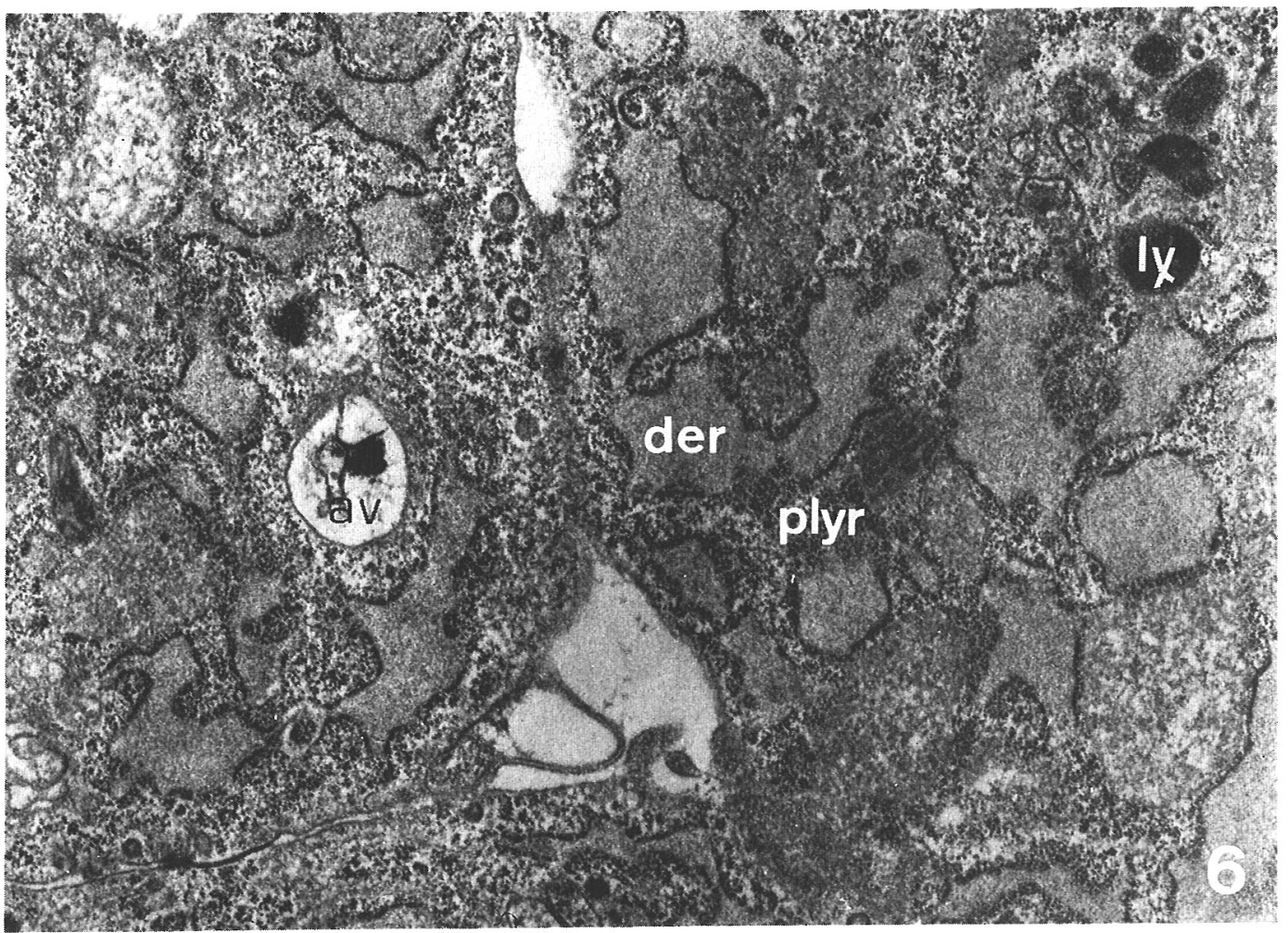

Fig. 6. 350-day culture. Cells contain a number of dilated endoplasmic reticulum (der) and polyribosomes (plyr). Lysosomes(ly) and autophagic vacuoles (av) are prominent. Note the presence of intercellular structures similar to the bile canaliculi found in situ. $\times 20,000$

in cacodylate buffer $\mathrm{pH} 7.2$, and dehydrated through a series of graded ethanols, then embedded in Epon 812. The preparations for sectioning were the same as those of Eguchi and Okada (3).

Cells were polygons, granular, and adhered to each other. They proliferated actively as growing islands with extremely smooth periferal contours that formed typical pavement-like sheets (Fig. 1). Growth curves indicated that the minimum doubling time during the logarithmic growth was about $24 \mathrm{~h}$; the frequency of diploidy $(2 n=42)$ was about $50 \%$.

Electron microscopy revealed that the liver cells in these cultures had ultrastructual features similar to liver parenchyma in situ. The cells came in close contact with the entire junctional complexes of the zonula occuludence and macula adherence types (Fig. 2,6), as is typical of epithelial cells. Two characteristic features were the presence of glycogen granules and the smooth surface of the endoplasmic reticulum (Fig. 4, 5),

Fig. 2-4. 70-day cultures. Cells are rich in dilated rough ER (der) and smooth rough ER (ser), and free ribosomes are abundant. Intact Golgi complexes (gc) are located in the juxtanuclear region and a deposit of collagen-like materials (arrow) is in the intercellular spaces. ly, lysosome; m, mitochondria; mf, microfibrils. $(2) \times 21,000,(3) \times 20,000,(4) \times 16,700$

Fig. 5. 350-day culture. An accumulation of glycogen granules, $\times 24,000$ 
known to be ultrastructual markers of parenchyma liver cells (1). The SERs were sometimes continuous with rough surface ER and were rich in dilated rough ER filled with electron dense materials (2). They also had well-delevoped Golgi complexes located in the juxtanuclear region (Fig. 2, 3,6). In addition the cytoplasm contained a large number of free ribosomes and polyribosomes (Fig. 3, 6). Besides these cell organelles, there were intercellular structures resembling the bile canaliculi (8) found in situ (Fig. 6) and a heavy deposit of collagen-like materials (7) in intercellular spaces (Fig. 3). Thus, the cell characteristics described above considered together suggest that it is that the epithelial cells in this study probably are derived from liver parenchyma.

Acknowledgements. We thank Professor T.S. Okada of Kyoto University for his advice and reading of this manuscript.

\section{REFERENCES}

1. Bruni, C. and K.R. Porter. The fine structure of the parenchymal cell of the normal rat liver. Am. J. Pathol. 46, 691-729, 1965

2. Chapman, G.S., A.L. Jones, U.A. Meyer and D.M. Bissell. Parenchymal cells from adult rat liver in nonproliferating monolayer culture. II. Ultrastructual studies. J. Cell Biol. 59, 735-747, 1973

3. EgUChI, G. and T.S. OKadA. Ultrastructure of the differentiated cell colony derived from a singly isolated chondrocyte in vitro culture. Dev. Growth Differ. 12, 297-312, 1971

4. ICHIHARA, A. Retention of the characteristics of liver cells during culture, differentiation, and carcinogenesis. in Control Mechanisms in Cancer. W.E. Criss, T. Ono and J.R. Sabine (eds) 317-327 Raven Press, New York; 1976

5. KAIGHN, M.E. Human liver cells. in Tissue Culture Methods and Application. P.F. Kruse Jr. (ed) 54-58, Academic Press, New York; 1973

6. Potter, V.R. Workshop on liver cell culture. Cancer Res., 32, 1998-2000, 1971

7. SaKakibara, K., M. Saito, K. Umeda, K. Enaka and Y. Tsukada. Native collagen formation by liver parenchymal cells in culture. Nature 262, 316-318, 1976

8. TANIKAWA, K. Ultrastructual aspects of the liver and its disorcers. 17-19. Springer-Verlag, New York; 1968 